\title{
Fire and Light, Four Poets to the End and Beyond
}

\section{Anthony Libby}

Our poetry is poetry of the body, full of blood, blood for intimacy, but more often blood for death. In Sylvia Plath blood is the sign of death intimately rendered. But if the early sixties were marked by poetry, like hers, of personal engagements with despair and death, the last years of the decade were dominated by evocations of a more general human movement toward dark ends and changes in being. In 1967 four central poets-Robert Bly, Ted Hughes, James Dickey, and W. S. Merwin-published collections of poetry about cultural death and transformation which in very different ways reflected a wide sense of deep crisis and change inadequately described as "apocalyptic." These books, and the more recent work of these four poets, seem to form a dominant contemporary pattern not only because of intersecting visions but because of similar styles created to cope with these visions. The three Americans and Hughes, the most American of contemporary British poets, have developed variations of a deeply visceral surrealism. Each man writes highly individual poetry, and each individual style is in the process of change, usually toward greater bluntness and greater complexity. But each poet has written lines that could be attributed to one or more of the others.

Given common preoccupations and similar cultural conditions, such resemblances come as no surprise. Nor should it surprise us that the sense of the radical transformation of man should eventually appear in surrealist poetry, for surrealism is based on the idea of transformation, "leaps" as Bly puts it, from one category of being to another, often from life to death. Now the leaps grow larger, more explicit and more general in their intimations. These surrealist intimations of universal death and change are difficult to describe in any common terms. Though they suggest apocalypse, they have little in common with traditional Christian apocalyptic writing, and they differ significantly from the apocalyptic sense of the pre-Hiroshima modern poetry of Yeats and the early Eliot. Their visions of ultimate crises come in part from the stress of nuclear terrors, but more perhaps from Vietnam, and the cultural collapse Bly and Merwin, at least, felt Vietnam had begun to represent by 1967. This poetry seldom imagines apocalypse in terms of a single Hiroshima-like flash; rather the end is like Vietnam a long slow wearing away-as Hughes says, "no calamitous change/ But a malingering of now." The attendant pressures take not physical but psychological forms, guilt, despair, and the desperate hope for changes once feared.

The particular types of changes imagined suggest that this lingering apocalypse is better described in Darwinian than Christian terms. Often uncomfortable 
or appalled in the face of social actualities or possibilities, these poets attempt to renew ancient connections with nature, the physical world, and animals imagined in generally alien and non-Romantic terms. So the eschatological imagination is complicated by the imagination of transition, an almost mystical sense of the possibility of participating in the animal flow of existence, discovering there some general relief from impossible cultural stress. In the types of animal participation the four poets create, we see their radical differences, and a basic dichotomy that seems now to confront all of us. Bly's vision, and occasionally Merwin's, is animated by the hope for evolution, apocalypse as transition to higher being. Dickey and Hughes tend more to construct a calculus of survival, regarding apocalypse as a condition which forces (or allows) regression, evolution backwards to a simpler more violently elemental state.

The opposition between evolutionary poetry and the poetry of survival can be described in traditional terms, political (revolutionary vs. reactionary) or even theological (man as transcendent vs. man as original sinner). But to understand the individual forms of these visions, to understand not only the difference between Bly and Dickey, but between Bly and Merwin, or Dickey and Hughes, we must look not to patterns but to poetry, and to the prose to which most of these poets have resorted in the attempt to explain what they see approaching, or already come. Of the four, Bly is most explicitly the mystic of evolution, the poet of "the other world" always contained in present reality but now about to burst forth in a period of destruction and transformation. Bly's poetry of the transformation of man follows logically from his early poetry of individual and private transcendence. Repeatedly, Silence in the Snowy Fields (1962) announces an "awakening" that comes paradoxically in sleep, in darkness, in death, an awakening depicted in surrealist images as compelling as they are mysterious, evasive. Bly's sense of mystical transformation is not really completely articulated until, primarily in the 1967 collection The Light Around the Body, it achieves an apocalyptic dimension, the awakening no longer individual or private, but part of the spiritual evolution of the race.

This general awakening, like the analagous experience of the isolated mystic, comes in the long dark night of a dying civilization. The poems of ecstatic prophecy in Light achieve much of their force by juxtaposition with the poems of political despair which dominate the collection. Constantly and convincingly Bly suggests that the psychological impact of Vietnam on America is as destructive as the physical presence of America in Vietnam; the victims in "Those Being Eaten by America" are not Vietnamese but Americans.

That is why these poems are so sad

The long dead running over the fields

The mass sinking down

The light in children's faces fading at six or seven

The world will soon break up into small colonies of the saved 
Bly's spiritual perceptions find physical articulation not only because Bly the poet uses images which make the abstract concrete, but because Bly the mystic of "the two worlds . . . both in this world" has always sought transcendence through immersion in the physical. Frequently his concrete imagery suggests the traditional apocalyptic vision of destruction in order to define the end of a psychological process already begun. To the "executives" of "Romans Angry About the Inner World" the emerging other world "is like a jagged stone/ Flying toward them out of the darkness." And the eschatological "images" of "When the Dumb Speak" include

Fires in the sea,

The ships smouldering like bodies,

Images of wasted life,

Life lost, imagination ruined,

The house fallen,

The gold sticks broken,

But the confluence of physical and psychological or spiritual in Bly is most striking when he depicts the paradoxically evolutionary aspects of apocalypse, apocalypse now considered not as end but process. As he begins to depict mystical development in temporal terms, the corporeal flow of being always evoked in his poetry finds definition in a vocabulary almost Darwinian. In "Looking at Some Flowers" Bly suggests the interpenetration of spiritual and physical in all the categories of being, those biological categories also intersecting with each other in time's flow, as life penetrates death.

Light is around the petals, and behind them:

Some petals are living on the other side of the light.

Like sunlight drifting onto the carpet

Where the casket stands, not knowing which world it is in,

And fuzzy leaves, hair growing from some animal

Buried in the green trenches of the plant.

Or the ground this house is on,

Only free of the sea for five or six thousand years.

"Evolution from the Fish" explores the human and spiritual implications of this flow, depicting evolution as an intimately personal experience contained in the individual and in the moment as it spreads to include all time. In this strangely moving poem a man existing in the present experiences an ice-age past and a glittering future:

This nephew of snails, six feet long, lies naked on a bed

With a smiling woman, his head throws off light

He becomes "mammoth fur" and then "the animal with furry head," but the journey, weighted with the past, continues onward: 
... the spirit moving around them,

Moves, dragging a great tail into the darkness.

In the dark we blaze up, drawing pictures

Of spiny fish, we throw off the white stones!

A fire is passing up through the soles of my feet!

The presence of "a smiling woman" is not simply a realistic detail in this poem's present, but an aspect of its myth of transformation. As Bly's sense of the imminent other world developed, he began to create a general evolutionary theory focused on the opposition between feminine consciousness and masculine consciousness. The two are defined in Jungian terms; the masculine, Bly writes in the Spring 1972 issue of his journal The Seventies, involves "a de-mythologized intelligence, that moves in a straight line made of tiny bright links, an intelligence dominated by linked facts rather than 'irrational' feelings." This intelligence, Bly says, has dominated Western culture, but we are now in a time of change, a time in which natural, mythic, creative and "irrational" feminine consciousness returns (in both men and women) to do battle for the psyche of our civilization. This battle, both destructive and liberating, apocalyptic and evolutionary, Bly describes in terms of the return of the Great Mothers, the preJudeo-Christian goddesses of love and death. ${ }^{*}$ Hence the title of his long Vietnam poem, "The Teeth-Mother Naked at Last," and the frequent references to Mothers in his more recent poetry.

Among these recent poems is the group "Some Poems for Max Ernst" in New Directions 23 (1971). Here the Mothers appear in their darkest forms; Bly's sense of transcendence seems to recede as the Father-consciousness culture railroads to destruction. In "Train Wreck in Midocean," as the train falls into dark waters more "murderous" than illuminating,

\section{A huge and sardonic \\ Woman stands looking down. \\ Just before dawn, the whole Burlington train will go back to her belly button, but now \\ the screams have to go on}

And in "Mother Coming," though the speaker welcomes the Mother "joyfully" and invites her to "come live inside one of my teeth," he sees her as destroyer, her coming signaled by "murdered men" and "infant tornadoes."

In a poet who has always realized how inadequately the possibility of transcendence justifies the actuality of suffering imposed on those incapable of

'For a more comprehensive description of Bly's theory of the Great Mothers, and a more detailed analysis of the way that theory develops out of his early poetry, see my "Robert Bly Alive in Darkness," The Iowa Review, III:3. Better still, attend a Bly reading, and hear him advance his own theories. His performance gives them a terrible and exhilarating immediacy that no summary can convey. 
choosing or rejecting it, this ambivalence is necessary. If our culture, described as radically and inevitably destructive in Bly's "Teeth Mother," must itself inevitably be destroyed by its own life-affirming forces, Bly logically views this affirmative destruction with as much terror as hope. Only this combination of emotions can provide adequate response to the mythic approach of the Great Mothers, since the life-giving Mother is always balanced by the death Mother, the Mother of ecstasy opposed to the Medusa-like stone Mother, who brings not new awareness but numbness. In the Seventies' selection from his new long poem "Sleepers Joining Hands" Bly admits the possibility of apocalypse without evolution.

The sun hidden by great insects ...

the battle we can lose, maybe

have already lost,

numbness, nothingness, paralysis!

The hawks will dive on us, the mother-hawk will come

.

In that age no one can save himself

But a line which pictures "the ecstatic orifices closed to the blue stormlight," suggesting spiritual retreat from apocalyptic battering, is immediately followed by "the outer eighth-inch of the brain giving off smoke," an image of pain, but perhaps also an image of new spiritual vitality. As Bly explains in the Seventies essay "The Three Brains," the neo-cortex, the outer eighth-inch of brain tissue, was a fairly late development in human evolution and may contain the physical capacity for new growth. Bly describes this "new brain" as the center of spiritual activity as well as the most advanced analytic thinking. To this brain he opposes the ancient "reptile brain," the limbic node, which focuses entirely on survival, and the "mammal brain," the cortex, characterized by "sexual love and ferocity."

So, another theory as eccentric as it is intriguing. But like the idea of the Great Mothers, which was based on the cultural investigations of Erich Neumann, this theory begins in comparatively orthodox scholarship, the investigations of the American neurologist Paul MacLean. And actually the whole complex of theory and myth fits together, as Bly suggests when he characterizes our (Fatherconsciousness) culture, and the United States in particular, as "a vast machine for throwing people into the reptile brain," the brain energized by fear and obsessed with the idea of survival. As for the Great Mothers, whether loving or ferocious, their domain is the mammal brain: "Women have strong mammal brains, and probably a correspondingly smaller energy channel to the reptile brain." The divisions here may seem artificially neat, but Bly's poetry emphasizes not the patterns but the chaos which results from the collision of the various brains, the conflicting types of consciousness surfacing in America now. And through it all runs a thread of hope that we cannot dismiss in a time of cultural desperation, the hope that out of the conflict will emerge the dominance of the new brain; "the mark of the new brain is light." 
Bly's abstractions provide terms which define with surprising accuracy the opposition between him and the poets of survival. In "The Three Brains" he says that "the reptile brain seems to have no poet of its own" though he suggests Robinson Jeffers as a possible candidate. But closer than Jeffers to the reptile brain's cold violence and grim obsession with survival on the most desperate level is Ted Hughes, whose poetry is by no coincidence dominated by reptiles, fish, and predatory birds. His obsession is most evident in Crow, the publication of which prompted A. Alvarez to write that Hughes was "the only British poet" to have joined "the select band of survivor-poets whose work is adequate to the destructive reality we inhabit." But Crow is only the latest and most extreme formulation of a perception always central to Hughes' poetry and especially evident in the 1967 Wodwo. If Wodwo is about survival it also concerns transformation, the changes and departures from any civilized norm necessitated by the condition of surviving. Physical violence is of course central, but the real tensions are psychological, the tensions of contemplating one's own animal experience with the sensitivity of human consciousness. In the Beckett-like prose piece "Snow," for instance, the greatest threat to the character's survival consists of uncertainty about who he is or why he should continue to struggle. "I must survive-that's a truth as sacred as any" is presented as both a statement of animal faith and, in rational terms, a desperate evasion. And in the short play "The Wound" Ripley's grotesque hallucinations are perhaps his only way to stomach the even more grotesque realities of general slaughter and cannibalism, rational contemplation of which would dull the "animal instinct" that keeps him alive.

Abstracted from the particulars created by Hughes' bloody imagination, the pressures that necessitate such rational evasions could be described as apocalyptic. But like Bly's, Hughes' "apocalypse" is not a defined group of events, but a process that has already begun, that continues to be the condition of being. Even the "earth-melting dawn" of "Boom" describes not an end but a slow movement, motion nearly stopped at the heart of destruction. This sense of endless deadly stasis appears throughout much of Wodwo, for instance in "Song of a Rat," in which the trapped rat both dies and, forced "down into godhead," seems to achieve frightening cosmic survival as a sign for our time.

\author{
And the sleep-souls of eggs \\ Wince under the shot of shadow \\ That was the Shadow of the Rat \\ Crossing into power \\ Never to be buried
}

Under the pressures of this psychic violence, the degraded but heroic survivor Hughes imagines must return to his own animal nature, discovering not the transcendent primitivism Bly imagines, but an unchangeable primitivism. As Bly's evolutionary hero, containing all past, moves into the future, Hughes' survivor simply returns to the evolutionary past within and around him. In "Wodwo," Hughes' new creature is a beast-man with human self-consciousness, but 
an animal sense of freedom from restraint, supreme self-importance, and primarily physical self-definition:

$$
\text { ... and past these trees }
$$

till I get tired that's touching one wall of me

for the moment if I sit still how everything

stops to watch me I suppose I am the exact centre

but there's all this what is it roots

Whatever revelation Hughes seeks in imagining these transformations is contained in such primitive roots, as he says in "A Wind Flashes the Grass" when he describes "the incomprehensible cry . . . below words,/Meanings that will not part from the rock." As "Wind" suggests, that cry is to be heard under conditions suggestive of Bly's black and windy revelation, as "leaves pour blackly across" and "the shadow of [the ploughman's] bones tosses darkly on the air." But even the darkest sections of Bly's poetry suggest the possibility of a mystic calm which is radically opposed to the static violence at the heart of Hughes' vision.

In their cultural and mythical theorizing, however, the two poets can sometimes sound oddly alike. In an interview in London Magazine which coincided (January, 1971) with the publication of Crow, Hughes explained a vision of "the whole mass of the people" diverted from the real "vehemence of life" by "the ordinary violence of our psychotic democracy." "We are dreaming a perpetual massacre" and watching it on television with "a sort of anesthetized unconcern." Bly too has suggested ways in which cultural and political violence are both cause and result of a fundamental evasion of the inevitable, and spiritually fulfilling, griefs of existence. He would probably agree with Hughes' "pervasive and deep feeling that civilization has now disappeared completely," and with his hope for a "completely new Holy Ground, a new divinity, one that won't be under the rubble when the churches collapse." Hughes' way to this holy ground involves the shamanistic evocation of the elemental forces buried by civilization; the poet as primitive magician dreams the repressed dreams of his people (searching, Bly would say, for underlying "deep images") and now he must record "how the forces of the Universe try to redress some balance disturbed by human error."

But Hughes' announced theological intentions seem deeply contradicted by Crow itself, which despite its surrealism basically resembles nothing of Bly's. Hughes complains about the distortions of Christianity: "When Christianity kicked the devil out of Job what they actually kicked out was Nature . . . and Nature became the devil." But often his poetry sounds like a simple reversal of Christianity, actually based on acceptance of the basic Christian definition of nature, if not of God. Nowhere is nature more demonic than in Crow, and its demonism stems not from cultural preconceptions but from the elemental facts of creation as Hughes reimagines it. The basic vision (here characteristically reptilian) is predicted by Wodwo's "Theology." 
Adam ate the apple.

Eve ate Adam.

The serpent ate Eve.

This is the dark intestine.

What Hughes really disagrees with in Christianity is the idea that God can improve this situation; the underlying myth of Crow involves a bumbling God who has created a universe so violently unbalanced that existence is pain and the imagery of apocalypse is always appropriate.

Nor do the pre-Christian gods or forces which return in Wodwo and Crow seem any less malevolent; Hughes' "new divinity" is ancient monstrosity. As he explains his mythical framework he attempts to suggest the reasons for this. Though we must confront the old elemental forces, "when the old rituals and dogma have lost credit and disintegrated, and no new ones have been formed, the energy cannot be contained, and so its effect is destructive." Particularly because Hughes speaks of these elemental forces as feminine and describes his darkly shamanistic poems as "invocations of the Goddess," there appears to be an obvious comparison with Bly's sense of the destructiveness of the Great Mothers. But unlike Bly's, Hughes' actual depictions of the Mothers suggest no love to balance their ferocity, little that is even potentially positive in their energy. In Wodwo, "Wings" depicts Einstein praying " "Mother! Mother/ O mother/ Send me love.'/ But the flies/ The flies rise in a cloud." The flies could be explained as an understandable response to Einstein, the priest of the Father-consciousness civilization's attempts to learn absolute control over (mother) nature, and so Hughes must intend it. But the image of the Mother is nothing but dark, as it continues to be even in those poems most clearly intended to show how the Father-consciousness civilization destroys nature, the individual psyche, and those on the side of the Mother. Apparently "Crow's Account of St. George" is meant as a vindication of the dragon, a representation of the way Christian Father-consciousness brutally represses nature forced into the role of the devil. Like Bly's masculine consciousness, the warrior "saint"

... sees everything in the Universe

Is a track of numbers racing towards an answer.

With delirious joy, with nimble balance

He rides those racing tracks. He makes a silence.

But monsters rise up against him, among them

An object four times bigger than the othersA belly-ball of hair, with crab-legs, eyeless, Jabs its pincers into his face, Its belly opens-a horrible oven of fangs, The claws are clawing to drag him towards itHe snatches from its mount on the wall a sword, 
He hacks it to pieces, and a rather contrived punch-line at the end reveals that he has slaughtered his wife and children. But the horror that finally dominates comes not from the slaughter but from his vision of the Mother, which Hughes has rendered with an obsessive sympathy for the endangered male.

Similarly, in "Logos," which anticipates the counter-theology of Crow, the wrath of the Mother appears far more disturbing than the ineffectuality of the Father-god. "Within seconds the new-born baby is lamenting/ That it ever lived-/ God is a good fellow, but His mother's against Him." Examples proliferate. In "Gog," Wodwo's dragon poem, the image of the Mother becomes ultimately horrible, so that even the steel-encased "Holy Warrior" who tilts at her seems more victim than mechanical destroyer:

His weapons glitter under the lights of heaven.

He follows his compass, the lance-blade, the gunsight, out

Against the fanged grail and tireless mouth

Whose cry breaks his sleep

Whose coil is under his ribs

Whose smile is in the belly of woman

Whose satiation is in the grave.

Hughes explains that "Gog" concerns "the dragon of Revelations," who is in the Bible the (masculine) serpent, Satan, but who becomes in the poem the Mother gloating over "death and death and death-/Her mirrors." Despite Hughes' theory about the changes our culture must accept to cope with the mythic violence of repressed nature, it seems impossible to imagine any way, "old rituals and dogma" or new, to propitiate this Goddess. As in Bly, Hughes' Mothers have returned to preside over the apocalypse. But while Bly's End may lead to a new dispensation, Hughes' continues indefinitely; even "Gog," which defines the last days in comparatively Biblical terms, conveys a sense not of ending but of endless continuation of dying.

Confronting this stasis, Crow girds himself not for revelation but for minimal survival. The ultimate creation of the reptile brain, Crow lasts by accepting the most primitive terms of existence. Hungry in a dead world, he must eat what comes to hand, and thus survival is defined. As Tony Harrington writes in a London Magazine review of Crow, "It is the appetite that does not baulk at carrion that is central to Crow's capacity for pulling through, and the symbol of man's desperate need to assimilate death, battles, disasters, destructions, even the world's total annihilation." This assimilation really implies participation, life feeds on death, and the choice of life is a choice to kill. In "Crow Tyrannosaurus" Crow thinks of man as "a walking/ Abbatoir/ Of innocents," and briefly contemplates turning from eating to "the light."

But his eye saw a grub. And his head, trapsprung, stabbed.

And he listened

And he heard 
Weeping

Weeping he walked and stabbed

Thus came the eye's

roundness

the ear's

deafness.

Throughout Crow, he continues to eat as the same horrors appear in poem after poem, the survivors dragged through fire after fire until the final stages, described in "Notes for a Little Play," in which "the flame fills all space." But life obstinately continues:

.. . two strange items remaining in the flames-

Two survivors, moving in the flames blindly.

Mutations-at home in the nuclear glare.

Horrors-hairy and slobbery, glossy and raw ...

They fasten together. They seem to be eating each other.

But they are not eating each other.

They do not know what else to do.

They have begun to dance a strange dance.

Despite such moments of weird elegance, Crow is an unpleasant book to read; finally it seems monotonously excessive, its style, deliberately made as ugly as its vision, usually lacking the savage grace of Wodwo. But it achieves an ultimate definition of what it is to be a survivor, a definition perhaps never fully confronted by another man who has called himself "the poet of survival," James Dickey.

If only because he is more often concerned with the survival of the individual than the survival of the race, Dickey is far less explicitly interested in apocalypse than Bly or Hughes. But his poetry frequently conveys the sense of man at the end of a long progression, awaiting some basic change, and his preoccupation with survival inevitably implies an awareness of imminent ends. Dickey himself finally states this in his novel Deliverance, where he frames an exercise in primitive survival with extensive dialogue about the inevitability of the collapse of civilization. But even in his generally non-apocalyptic poetry he seems close to the fundamental preoccupations of Bly and Hughes, though he often approaches these preoccupations from a viewpoint in various ways opposed to theirs. Though 
his poetic development has in general been development away from the mythic imagination, he remains a poet of ultimate violence and of transformation, of human movement into animal consciousness, opposing to Bly's transcendent Darwinism a regressive sense of the primitive survival of the fittest. Unlike Hughes, who is both fascinated and horrified by the guilt implied by minimal survival, Dickey seems to find in blood conflict a vitalizing force which makes guilt irrelevant; his is the truer reptile brain. Though he writes in Sorties that he is interested in "the poetry of murderous drives," he characterizes Hughes as "frantic" and says that Crow "has nothing to do with the world."

In Sorties, which is very emphatic about the limitations of most contemporary poets, Dickey also describes Bly quite simply as a "bad" poet. But the two were comparatively close at one time; there exist striking similarities between poems in Dickey's Drowning with Others and Bly's Silence in the Snowy Fields, both published in 1962. For instance Dickey's "Inside the River" describes a transcendent immersion in dark waters suggestive of many of Bly's poems. Even the imagery is somewhat similar. While Dickey writes "Live like the dead," Bly writes "the living awakened at last like the dead" in "Awakening." And Dickey's vision of the earth giving way to water, "grains/ That stream like dust/ In a holy hallway" suggests "The sea of solitary corridors, / And halls of wild nights" in Bly's "Return to Solitude." Like Silence, Drowning is a book of mystical movement of consciousness into animals, into death, into the flow of physical existence. As "Crunk" (probably Bly) wrote in The Sixties in 1964, Dickey's early poetry is characterized by "sudden passages from the bestial to the angelic." But the next Sixties article on Dickey was a 1967 review of Buckdancer's Choice, now signed by Bly, and entitled "The Collapse of James Dickey."

The antagonism between the two poets is largely political. As the war in Vietnam changed and darkened the movement of Bly's mysticism, it seems to have solidified Dickey's conservatism, his sense that powerful countries, like great men, are unnecessarily weakened by extreme moral self-consciousness. (From Sorties: "The world, the human mind, is dying of subtlety. What it needs is force.") Their extremes appear in the contrast between "The Teeth-Mother Naked at Last" and Dickey's "The Firebombing," which concerns his bombing civilian Japan during World War II but, as Bly pointed out, immediately suggests Vietnam. Both poems focus on napalm, on images of machines destroying flesh, the complex American engines of war bringing fire to primitive villages. Bly presents the pilots' experience as deeply neurotic, stemming from an unacknowledged desire for death; Dickey, though obviously aware of the ironies involved, presents the mission as a strangely beautiful experience, full of power and light.

The critical problem with "The Firebombing" is to understand how deeply Dickey really feels those moral ironies. Critics (like Laurence Lieberman) sympathetic to him argue that the poem describes an unsuccessful but honest attempt to confront guilt. In Alone with America Richard Howard equivocates, saying the poem concerns "the failure or refusal to imagine apocalypse." Bly, who does see apocalypse in firebombing, claims that it is not a failure but a refusal to imagine, and to accept responsibility, that the poem's superficial in- 
volvement with the moral issue gives way to "the excitement of re-living the bombing." Even if it made sense to assume that the dispute is, as Dickey has complained, purely political, it would seem clear that Dickey's attempt to imagine the suffering he causes-"The death of children is ponds/ Shutter-flashing" -is half-hearted in comparison with Bly's evocations of similar deaths:

The six-hour infant puts his fist instinctively to his eyes to keep out the light.

But the room explodes,

The children explode.

Blood leaps on the vegetable walls.

In any case Dickey's is the poem of a man who survives not only because he accepts power but because he cannot or will not assume the psychological burden of suffering; Bly's poem is apocalyptic because he feels that the burden of such caused suffering destroys us. Even if it did not include the image "Enemy river and trees/ Sliding off me like snakeskin," "The Firebombing," with its atmosphere of cold "blue light," would strongly suggest the chill survival obsession of the reptile brain. This impression is corroborated by the animal poetry of Buckdancer's Choice, which like Hughes' focusses primarily on cold-blooded predators. But even Dickey's earlier, transcendent animal poetry, which consistently emphasized mammals, was dominated by natural violence. For instance "The Heaven of Animals," a beautifully controlled poem in Drowning, depicts an eternity of perfect kills, perfectly enjoyed by both prey and, more convincingly, predators. But more frequently Dickey's poetry of animals, unlike Hughes' evocations, enacts human immersion in nature, man the hunter sensing the consciousness of his prey. In Helmets (1964) "Springer Mountain" describes the hunter becoming a deer, "My brain dazed and pointed with trying/ To grow horns, glad that it cannot,/ For a few steps deep in the dance," then returning to the hunt. In "Approaching Prayer" from the same collection, the emphasis on the experience of violent death is doubled as the poet imagines a kill from the viewpoints of hunter and hunted simultaneously.

In Buckdancer's Choice the hunter is almost gone, but the sense of human participation in animal violence is increased. For instance in "Gamecock" the cock shares with an "old man in a terminal ward" "the enraged, surviving-/ anotherday blood." In both creatures, "savagery" is at its peak as they confront doom, "battling to the death." "Reincarnation (I)" depicts an actual movement backward into the life of the reptile, where the snake-man, finding that his new body flows "as naturally as the creation/ Of the world," discovers a new purity of "ice cold" violence. "The Head-Aim," in Falling, describes a similar movement "into the world that crawls, by a man "sick of [his] arms."

Lifting out of the weeds.

This is the whole secret of being

Inhuman: to aim the head as you should, 
The abrupt break between "being" and "Inhuman" seems intended to suggest that this fundamental violence is the whole secret of being. Frequently, as in "For the Last Wolverine," which ends the description of this "non-survivor" with the poet's own plea "Lord, let me die but not die/ Out," violence is presented as the last response to the threat of extinction. But the threat of extinction, individual or general, is frequently welcomed as a condition of vitality. Most of the rather frantic joyousness of Dickey's 1970 collection The Eye-Beaters, Blood, Victory, Madness, Buckhead, and Mercy seems to depend on the felt imminence of death.

The ramifications of this vision are explicitly developed in Dickey's Deliverance (1970), in which he artificially creates the conditions of apocalypse in order to imagine the excitement of survival-conflict on an animal level. Though Dickey is scornful of Bly's political dissatisfaction with America, he seems to share some of Hughes' sense of the dull and doomed quality of contemporary culture, as he shares Hughes' instinctive movement away from that culture toward the primitive. At times Deliverance, with its full-bodied hero and wilderness homoeroticism, reads like an extreme parody of Leslie Fiedler's sense of the American novel. But as he makes clear through Lewis Medlock's long disquisition on "atomic-survival stuff," Dickey is serious, and less concerned with sex than survival. Lewis goes into the wilderness in deliberate anticipation of the time when "the machines" and "the political systems" fail, and "the whole thing is going to be reduced to the human body." He is ready, if not eager for that time. "Life is so fucked-up now, and so complicated, that I wouldn't mind if it came down, right quick, to the bare survival of who was ready to survive." After the explosion he envisions a new primitive life "that wasn't out of touch with everything." "You'd die early, and you'd suffer, and your children would suffer, but you'd be in touch." The predatory Lewis, with his face "like a hawk," may be undercut somewhat, but in general Dickey's heart is with him. In Sorties he says, with who knows what degree of seriousness, "I am Lewis; every word is true." As the novel progresses the idea of survival of the fittest forms the basis of the drama, though this requires a certain amount of authorial manipulation; by coincidence, or fate, it is the weak Bobby who is raped, and the gentle and conspicuously civilized Drew killed. For vengeance and life, the narrator must enter "the heart of the Lewis Medlock country . . . pure survival," and there, as he imagines himself "some kind of animal . . . could be a snake," his "heart expanded with joy at the thought of where I was and what I was doing."

If Dickey and Bly confront the various apocalyptic changes they imagine with radically different types of joy, W. S. Merwin looks to the future with resignation, neither joyful nor terrified. He senses the approach of our end, but he carefully limits his pessimism, for instance rejecting Hughes' conviction that human strife only mirrors nature's divine violence. In The Lice (1967), “Avoiding News by the River" ends

I dreamed that the heavens were eating the earth

Waking it is not so 
Not the heavens

I am not ashamed of the wren's murders

Nor the badger's dinners

On which all worldly good depends

If I were not human I would not be ashamed of anything

And in "The River of Bees" Merwin suggests the arrogance of preoccupation with survival; "we were not born to survive/ Only to live."

Partly because of the quiet aphoristic surrealism Merwin has been developing since The Moving Target (1963), The Lice has an elegaic force which Harvey Gross (in the Summer 1970 Iowa Review) describes as "post-apocalyptic." Merwin deliberately suggests time past in order to convey the feeling of an inevitable future; as he says in another context in "A Scale in May," "To succeed consider what is as though it were past/ Deem yourself inevitable." Actually, like Bly and Hughes he seems to write of an end not finished but in slow process, though unlike them he observes the passing of man dispassionately, and without recourse to myth or mother. In "The Gods" he says

The gods are what has failed to become of us

Now it is over we do not speak

Now the moment has gone it is dark

What is man that he should be infinite

The music of a deaf planet

The one note

Continues ...

Many of the poems in The Lice suggest, like Bly, a political dimension of the end. "The Asians Dying" describes a double apocalypse, the one we have caused in Vietnam echoed by the "fire" that approaches us in a sort of natural vengeance:

When the forests have been destroyed their darkness remains

Forever

The ash the great walker follows their possessors

Nothing they will come to is real

Nor for long

The heavily surrealist "Unfinished Book of Kings" is less specific but equally ominous, describing in semi-biblical terms the end of an empire that seems to be America. "The lips of the last prophets had fallen/ . . . in spite of the assurances proceeding from the mouths of the presidents . .. / And in spite of the little votes burning at the altars ... / And the jailers' eagle headed keys renewed in the name of freedom." Again Merwin describes a period of waiting amid signs of the inevitable-"the blood began to run down the white sky"-but here the citi- 
zens wait for death not in fear but eagerness. "We have waited enough war or no war/ Calling for the coronation of Their Own the last of the absences."

The only ameliorating factor in The Lice's quietly grim vision is the idea that though human life as we know it deserves its end, other life may continue. Not, of course, the lives we have already ended; "For a Coming Extinction" suggests that our sending the whale "to The End/ That great god" is an aspect of our own similar passage. But perhaps we may not manage to destroy everything, and Merwin finds a consciously misanthropic comfort in this; "December Night" ends "I find a single prayer and it is not for men." The "Herds" describe a time remote from the time of man, in which the poet has become a voice "to celebrate our distance from men," and to describe the recurrence of an ancient scene: "Out of the many hoof tracks the sounds of herds/ Would begin to reach me again."

With its "ancient sun" and ice-age "glass mountain," "The Herds" could as easily be set in the remote past as the distant future. Merwin comes closest to the evolutionary vision of the other poets when he suggests the possibility of cycles of human as well as animal existence before and after our own; many of the poems in the 1970 The Carrier of Ladders form a meditation on such changes and on the possibility of an accompanying revelation. "Last People" describes the feeling that "it was like this before:"

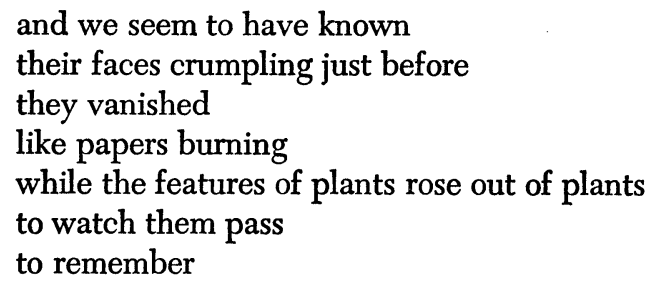

Other poems suggest that the cycles may continue, that for some there may be "another life," in which, as "Now It Is Clear" puts it, we may "be found and lost no more." And "Midnight in Early Spring” announces, somewhat ambiguously

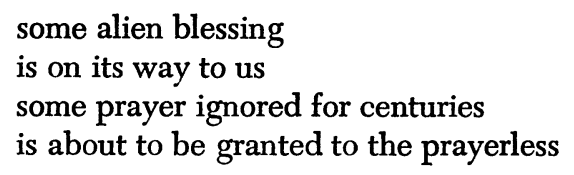

But in The Carrier Merwin balances the suggestions of mystic hope with poems as bleak as any in The Lice, poems of the revelation that never comes. "Third Psalm: The September Vision" describes "black days black days," and lakes which "carry away secrets/ they never brought ... a and there was never a silence like this/ oh objects come and talk with us while you can." Merwin's final divided vision of the endless end is contained in "The Hulk," in which a small child waits in the wreckage of a huge ship beached in a silent port. 


\author{
I can sail if we sail \\ I can wander \\ through the rusting passages forever \\ with my fear by the hand \\ and no father
}

Any voyage away from the reality of decay seems unlikely; though even he turns occasionally to mythic hope, Merwin's basic pessimism may make him the most realistic of these poets. But what realism should we seek from the rest of these surrealists, how deeply and how literally should we believe in the poetry of transformation? In The Sense of an Ending, Frank Kermode's book on traditional and early modern apocalyptic writing, he argues the conventional critical line that the idea of apocalypse, with its attendant myths, is a useful metaphor for poetic commentary on the changes of culture, but that both poet and reader must sustain "clerical skepticism" about this ordering fiction. Such skepticism avoids the embarrassments of belief, but now it may also avoid reality; it has been argued (statistically, by scientific minds not given to metaphor) that in our time some sort of nearly universal destruction is more probable than not. And Vietnam, a basic apocalyptic metaphor for Bly and Merwin, seems not only a logical model of fiery ends, but a direct manifestation of the collapse of a particular ethical self-image of western (now predominantly American) culture without which that culture may not survive in any recognizable form. In any case it seems impossible to read any of these poets seriously if we reject their sense of an end already begun.

But the question of belief does become a real one as we try to confront the myths that Bly and Hughes, at least, have created or revived. Is the Great Mother simply a metaphor for certain aspects of nature, or is she a psychic reality? No answer appears yet, but oddly enough Dickey, the poet whose recent work shows the least interest in myth, has written a poem which suggests an approach to the question. "The Eye-Beaters," the most striking and compassionate piece in Dickey's 1970 collection, describes a man's attempt to imagine bearable reasons why blind children in an orphanage incessantly strike their eyes. On its deepest level the poem becomes a symbolic statement of the need to return to some version of the primitive mythic past in response to present realities. The man knows that his "fiction" about these children is a rationalization of their pain, but he also knows its truth for him, his need to accept it to "make them/ make me/ Re-invent the vision of the race." He imagines that they see in "the middle/ Of the brain, where the race is young" beasts, a primitive artist, and "the niches filled, not with Virgins,/ But with the squat shapes of the Mother." This is his "therapy," which enables him "to survive." But finally the myth puts out reason "Iike eyes. Therapist, farewell at the living end. Give me my spear." There seems no rational way to face a cultural and perhaps racial disaster largely created by man's arrogant rationality. Believing this, confronting our end, our poets dream new myths of survival or transformation. Few of us can really believe these myths. Some of us may live to live them. 